\title{
Maternal near miss review from a tertiary care center in South India
}

\section{Jyoti Ramesh Chandran*, Sajala Vimal Raj, Sumangala Devi D., Aravind Ramachandran}

Department of Obstetrics and Gynaecology, Institute of Maternal and Child Health, Government Medical College, Kozhikode, Kerala, India

Received: 04 June 2016

Accepted: 01 July 2016

\section{*Correspondence:}

Dr. Jyoti Ramesh Chandran,

E-mail: drjyotichandran@gmail.com

Copyright: (C) the author(s), publisher and licensee Medip Academy. This is an open-access article distributed under the terms of the Creative Commons Attribution Non-Commercial License, which permits unrestricted non-commercial use, distribution, and reproduction in any medium, provided the original work is properly cited.

\section{ABSTRACT}

Background: Maternal near miss review acts as complimentary for mortality audits. It indicates the quality of obstetric care and helps obstetricians to revise policies and practices.

Methods: A retrospective observational study was carried out at institute of maternal and child health, Government Medical College Kozhikode from January to December 2014. Cases were defined based on WHO criteria 2009.

Results: Total live births during the study period were 15604 and there were 24 maternal deaths. Near Miss cases were 267. Maternal mortality rate was $153.5 /$ lakh live births and maternal near miss incidence ratio was $17.03 / 1000$ live births. Maternal near miss to mortality ratio was 11.1 and mortality index was $8.2 \%$. Hypertensive disorders comprised $46 \%$, followed by haemorrhage $36 \%$, sepsis $7 \%$ and other causes $10 \%$.

Conclusions: Even with improving care, maternal near miss incidence (17.03 per 1000 live births) is found to be higher in our institution compared to developed nations. However high maternal near miss to mortality ratio (11.1) and low mortality index (8.2\%) shows good quality of obstetric care in our institution.

Keywords: Maternal near miss, Maternal mortality

\section{INTRODUCTION}

Maternal and Child Health Care is one of the eight basic components of primary health care in declaration of Alma Ata. ${ }^{1}$ Maternal mortality ratio (MMR) of India has declined from 212 in 2007-2009 to 174 in $2015 .^{2}$ The MMR of Kerala stands at 66 per one lakh live births according to 2010-2012 survey of registration.

Women who survive severe complications during pregnancy, child birth and postpartum period could serve as surrogates to help us give a better understanding of the set of conditions and preventable factors that together contribute to maternal death. This is known as concept of maternal near miss. ${ }^{3}$
WHO defined maternal near miss in 2009 as "a women who nearly died but survived a complication during pregnancy, child birth or within 42 days after termination of pregnancy".

\section{The advantages of reviewing near miss events are}

Near misses are more common than maternal death, they have the same pathway which leads to death and provide information regarding care received and possible means of prevention, as the women survives, near miss review may be seen as less threatening than the death reviews, for the team who report them and one can learn from the women themselves as they themselves can be interviewed. 
Broadly, WHO recommends 3 different approaches of selection criteria for identification of maternal near miss cases. They are:

- Disease specific criteria

- Management based criteria

- Organ dysfunction criteria.

\section{Disease specific criteria}

Clinical criteria related to specific disease entity like preeclampsia, eclampsia, HELLP syndrome, severe haemorrhage, sepsis and uterine rupture. ${ }^{4}$

\section{Intervention based criteria}

In most developed countries, admission to intensive care unit or requirement of critical care, have been used to identify near misses. ${ }^{5}$ However the disadvantage of these criteria is the accessibility and availability of intensive care facilities for patients who need them. Other interventions like performance of intra-partum hysterectomy, blood transfusion or caesarean section have been used to identify near misses.

\section{Organ system dysfunction based criteria}

The system is based on the concept that there is sequence of events leading from good health. ${ }^{6}$ The sequence is clinical insult, followed by a Systemic Inflammatory Response (SIR), organ dysfunction, organ failure and finally death. Near misses would be those women with organ dysfunction and organ failures who survive the criteria for defining a near miss and are defined per organ system.

The advantages of this system are that it helps in establishing the pattern of the disease causing morbidity, comparisons can be made, definition can be standardized and used in many different settings, problem within the health system may be studied and audit can be carried out prospectively.

The disadvantages are that it is dependent on minimum level of care in a country and there must be functioning laboratories for some specific blood tests and basic critical care monitoring must be available.

\section{The practical aspects of WHO criteria includes ${ }^{7}$}

\section{Clinical criteria}

Acute cyanosis, gasping, respiratory rate $>40$ or $<6$ breaths /minute, shock, oliguria not responsive to fluids or diuretics, coagulation disorders, total paralysis, loss of consciousness for $\geq 12$ hours, jaundice with pre eclampsia and unconsciousness with no pulse and heart beats

\section{Laboratory criteria}

Oxygen saturation $<90 \%$ for $\geq 60$ minutes, $\mathrm{PaO} 2 / \mathrm{FiO} 2$ $<200 \mathrm{~mm} \mathrm{Hg}$, Creatinine $\geq 300 \mathrm{mmol} / \mathrm{L}$ or $\geq 3.5 \mathrm{mg} / \mathrm{dl}$, bilirubin $>100 \mathrm{mmol} / \mathrm{L}$ or $>6 \mathrm{mg} / \mathrm{dl}, \mathrm{pH}<7.1$, lactate $<5$, acute thrombocytopenia $(<50,000$ platelets), loss of consciousness and ketoacidosis and glucose in urine.

\section{Management criteria}

Continued use of vasoactive drugs, hysterectomy for postpartum haemorrhage or infection, transfusion of $\geq 5$ units of PRBSs, dialysis for acute renal failure, intubation and ventilation for $\geq 60$ minutes and not related to anaesthesia and cardiopulmonary resuscitation.

Maternal near miss incidence ratio $=$

$$
\frac{\text { Number of maternal near miss cases }}{\text { Total number of live births }} \times 1000
$$

Mortality index $=$

$$
\frac{\text { Number of maternal deaths }}{\text { Number of maternal deaths }+ \text { Number of near miss cases }} \times 100
$$

The objective of this study was to determine maternal near miss ratio (MNMR), maternal near miss to mortality ratio and mortality index and to evaluate the level of care by comparatively analysing near misses and maternal mortality.

\section{METHODS}

This is a retrospective observational study conducted at institute of maternal and child health, Government Medical College Kozhikode, Kerala, India from January December 2014. Data was collected from case records of the patient and statistical analysis was done using SPSS software. Cases were defined based on WHO Criteria 2009.

\section{RESULTS}

The total number of live births during the study period was 15604 and total maternal deaths were 24 with a Maternal Mortality rate of $153.5 /$ lakh live births. Total near miss cases were 267 with a maternal near miss ratio of 17.03/lakh live births. Maternal near miss to mortality ratio was 11.1 and mortality index was $8.2 \%$.

The main cause of maternal mortality (Figure 1) during the study period was hypertensive disorders of pregnancy (25\%) followed by haemorrhage and sepsis $17 \%$ each. Amniotic fluid embolism comprised $12 \%$ followed by anemia and heart disease $8 \%$ each. Other causes comprised $10 \%$. 

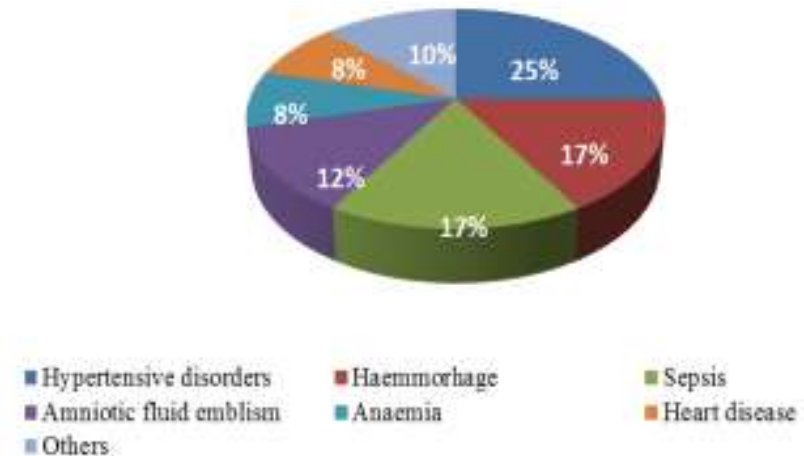

Figure 1: Causes of maternal mortality.

Main causes of maternal near misses (Figure 2) were hypertensive disorders of pregnancy $(46 \%)$ followed by haemorrhage $37 \%$, sepsis $7 \%$ and others $10 \%$.

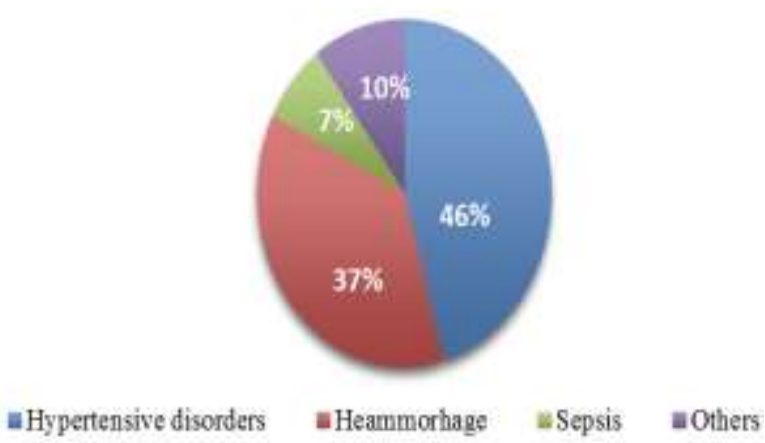

Figure 2: Main causes of maternal near misses.

Among the hypertensive disorders severe preeclampsia comprised $23.5 \%$, eclampsia $14.9 \%$, HELLP syndrome 7.1\%. Among the spectrum of haemorrhage (Table 1), postpartum haemorrhage comprised maximum (13.1\%) cases of near misses.

Table 1: Spectrum of haemorrhage.

\begin{tabular}{|lll|}
\hline Postpartum haemorrhage & 35 & $\mathbf{1 3 . 1} \%$ \\
\hline Abruptio placentae & 30 & $11.2 \%$ \\
\hline Rupture uterus & 15 & $5.6 \%$ \\
\hline Ectopic pregnancy & 10 & $3.7 \%$ \\
\hline Placenta praevia & 8 & $2.9 \%$ \\
\hline
\end{tabular}

The demographic characteristics (Table 2) reflects that majority of the patients were between the age of 20-34 years $(48.6 \%)$, were Multigravidas $(55.4 \%)$ and had preterm delivery $(63.2 \%)$.

Obstetric and perinatal outcome (Table 3) shows that Majority of Near Miss cases happened with caesarean delivery (53.1\%) and had babies weighing between 1.5$2.5 \mathrm{~kg}(40.4 \%)$. The live birth rate was $67.4 \%$ and $77.5 \%$ patients needed hospitalization for 10-20 days.
Table 2: Demographic characteristics.

\begin{tabular}{|lcc|}
\hline \multicolumn{3}{|c|}{ Age (years) } \\
\hline$<19$ & 40 & $14.9 \%$ \\
\hline $20-34$ & 130 & $48.6 \%$ \\
\hline$>34$ & 97 & $36.3 \%$ \\
\hline \multicolumn{3}{|c|}{ Parity } \\
\hline Primigravida & 119 & $44.5 \%$ \\
\hline Multigravida & 148 & $55.4 \%$ \\
\hline \multicolumn{3}{|c|}{ Gestational age } \\
\hline Term & 98 \\
\hline Preterm & 169 & $36.7 \%$ \\
\hline
\end{tabular}

Table 3: Obstetric and perinatal outcome.

\begin{tabular}{|c|c|c|}
\hline \multicolumn{3}{|c|}{ Mode of delivery } \\
\hline Vaginal & 115 & $43.07 \%$ \\
\hline C-section & 142 & $53.1 \%$ \\
\hline Instrumental delivery & 10 & $3.7 \%$ \\
\hline \multicolumn{3}{|c|}{ Birth weight $(\mathbf{k g})$} \\
\hline$<1.5$ & 47 & $17.6 \%$ \\
\hline $1.5-2.5$ & 108 & $40.4 \%$ \\
\hline$>2.5$ & 112 & $41.9 \%$ \\
\hline \multicolumn{3}{|c|}{ Neonatal condition } \\
\hline Live birth & & $67.4 \%$ \\
\hline Fresh still birth & & $10.1 \%$ \\
\hline Macerated still birth & & $22.4 \%$ \\
\hline \multicolumn{3}{|c|}{ Hospital stay after near miss event (days) } \\
\hline$<10$ & 20 & $7.4 \%$ \\
\hline $10-20$ & 207 & $77.5 \%$ \\
\hline$>20$ & 40 & $14.9 \%$ \\
\hline
\end{tabular}

There had been delay in providing care (Figure 3) to near miss cases $46 \%$ at level $1,32 \%$ at level 2 and $22 \%$ at Level 3. Sepsis contributed to $17 \%$ of maternal mortality and $7 \%$ of near miss cases. Sepsis continues to be a major problem in spite of use of higher antibiotics and improved care

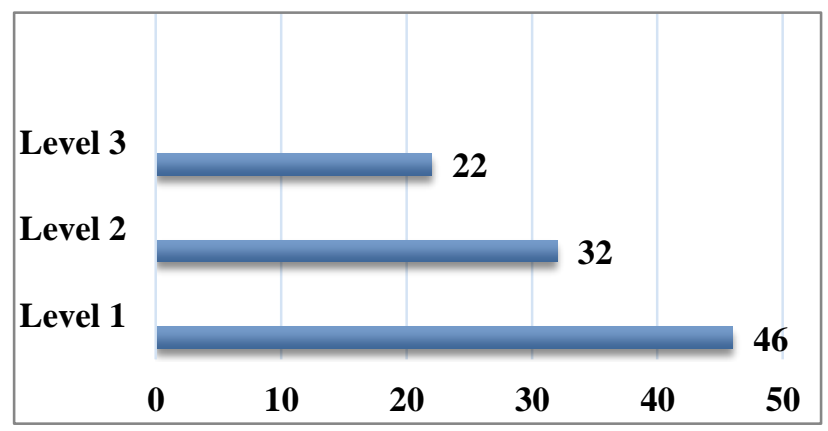

Figure 3: Levels of delay in care.

\section{DISCUSSION}

The primary determinant of near miss cases in our study was hypertensive disorders of pregnancy (46\%). A retrospective observational study conducted by FOGSI 
from 2005-2007 in India also observed hypertension as the leading cause of maternal death. ${ }^{8}$ Souza et al from Brazil also reported hypertensive syndromes as the most commonly associated (57\%) cause for near miss cases. ${ }^{9}$

Haemorrhage $(37 \%)$ was the next determinant for near miss cases. This also collaborates with FOGSI and Brazilian studies. ${ }^{8,9}$ Sepsis contributed $7 \%$ of near misses and $76 \%$ of patients with caesarean delivery developed sepsis. Irrational use of antibiotics leads to antibiotic resistance. Moreover the rate of $\mathrm{C}$-section was significantly higher in the women who developed severe morbidity during pregnancy compared to those who developed it during the puerperium. ${ }^{9}$

Majority (48.6\%) were in the age group 20-34 years. Marcia Lait et al found that more cases were in the age group 20-29 years except that using WHO criteria, more cases were identified in the age group 30-39 years. ${ }^{10}$ Multigravidas were more $55.4 \%$ than primigravidas $(44.6 \%)$. However in other studies, majority were primigravidas. ${ }^{10} 53.1 \%$ underwent cesarean delivery and $40.4 \%$ delivered babies with birth weight between 1.5-2 kg.Similar data was seen in Brazilian study. ${ }^{10}$

The live birth rate was fairly good at $67.4 \%$ but hospital stay was prolonged for $10-20$ days in $77.5 \%$ of patients, reflecting morbidity and financial burden to the health facility.

In a prospective study in Nigeria conducted by Ikeola et al, women who were referred from another facility had a fourfold risk $(\mathrm{OR}=3.84)$ for near miss as compared to those who were not referred. One probable reason was late referral. In our study there was $46 \%$ delay at level 1 , $32 \%$ at level 2 and $22 \%$ at level 3. Several narratives from near misses strongly suggest that the act of first approaching lower level centers (which lack emergency obstetric care) inadvertently delay the referral process.

Even with improving care, maternal near miss incidence (17.03 per 1000 live births) is found to be higher in our institution probably being a tertiary care center. However high maternal near miss to mortality ratio (11.1) and low mortality index $(8.2 \%)$ shows good quality of obstetric care in our institution.

\section{CONCLUSION}

Near misses can be prevented to some extent by spreading awareness about possible obstetric complications and risk stratification. Timely referral after first line therapy would play a very important role. Availability of blood bank facility, ventilator support should be mandatory in first referral units and coordinated critical care team care should be available in tertiary hospitals. Obstetricians should receive adequate training in managing obstetric emergencies good nursing care and psychological support is also an important need of the hour.

\section{Funding: No funding sources}

Conflict of interest: None declared

Ethical approval: The study was approved by the Institutional Ethics Committee

\section{REFERENCES}

1. WHO. Declaration of Alma Ata. International Conference on Primary Health Care, Alma Ata. USSR; 1978:6-12.

2. Patnaik D, Chakraborty B, Goswami S, Adhikari C. Changing trends of maternal mortality: comparative study. J Obst Gynae India. 2011:61(2):161-5.

3. Souza JP, Gulmezoglu AM, Qureshi Z. WHO MCS Research Group. The world health Organisation multi country survey on maternal and newborn health: Study Protocli. BMC Health Survey. 2011;11:286.

4. Waterstone W, Bewley S, Wolfe C. Incidence and predictors of severe obstetric morbidity :case-control study. BMJ. 2001;322;1089-94.

5. Souza JPD, Duarte G, Basile Filho A. Near miss maternal mortality in developing countries. European Journal Obstetrics and Gynaecology Reprod. 2002;104:80.

6. Mantel GD, Buchmann E, Rees H, Pattinson RC. Severe acute maternal morbidity; a pilot study of a definition for a near miss. $\mathrm{Br}$ Journal Obstet Gynaecol. 1998;105(9):985-90.

7. Say L, Souza JP, Pattinsons RC. Maternal near misstowards standard tool for monitoring quality of health care. Best Practice Clin Obst Gynecol. 2009;23:287-96.

8. Purandare $\mathrm{CN}$. Maternal near miss review: a way forward. J Obstet Gynaecol India. 2013;63(4):213-5.

9. Souza JPD, Cecatti TG. The near miss maternal morbidity scoring system was tested in a clinical setting in Brazil. J Clin Epidemiol. 2005;58:962-3.

10. Morse ML, Fonseca SC, Gottgtroy CL, Waldmann CS. Severe maternal morbidity and near misses in a regional reference hospital.Rev Brass Epidmiol. 2011;14(2):310-22.

11. Jabir M, Abdul Salam I, Suheil DM. Maternal near misses and quality of maternal health care in Baghdad Iraq. BMC Pregnancy Childbirth. 2013;13:11.

Cite this article as: Chandran JR, Raj SV, Devi $\mathrm{SD}$, Ramachandran A. Maternal near miss review from a tertiary care center in South India. Int J Reprod Contracept Obstet Gynecol 2016;5:265760 . 